\title{
STUDI KELAYAKAN PEMBUKAAN PROGRAM DIPLOMA III TEKNOLOGI INFORMASI UNDIKSHA SINGARAJA
}

\author{
Oleh:
}

Komang Setemen, Putu Hendra Suputra, Ketut Purnamawan

Jurusan Manajemen Informatika, FTK, Undiksha

\begin{abstract}
Abstrak
Bali sebagai daerah tujuan wisata (DTW) yang makin mengglobal memberikan sejumlah peluang dan tantangan, seperti : terbukanya sejumlah lapangan kerja baru, baik dalam jenis, jumlah, dan jenjang kualifikasi tertentu. Lapangan pekerjaan itu sebagian besar bertalian langsung dengan industri pariwisata serta sistem pendukungnya. Misalnya, jasa bahasa asing (Inggris dll), manajemen bisnis dan akuntansi, pemandu wisata, biro perjalanan, pengelolaan hotel, sport dan rekreasi, kesenian, produk industri kecil/kerajinan, termasuk teknologi informasi. Secara umum maupun secara khusus di Bali, sampai saat ini bidang teknologi informasi sudah memasuki hampir seluruh cabang kehidupan dengan kecenderungan yang semakin meningkat. Untuk mengetahui kompetensi dan potensi kebutuhan lulusan teknologi informasi oleh pasar kerja, dan seberapa besar potensi lulusan SMA atau SMK untuk melanjutkan studi di program teknologi informasi, maka dilakukan studi kelayakan dalam bentuk penyebaran kuisioner kepada instansi-instansi pemerintah maupun swasta yang memanfaatkan teknologi informasi pada bidang kerjanya. Kuisioner juga disebarkan kepada siswa-siswi SMA atau SMK untuk mengetahui seberapa besar keinginannya untuk melanjutkan studi pada program teknologi informasi. Hasil analisis menunjukkan bahwa proyeksi kebutuhan tenaga teknologi informasi dan komunikasi di Bali masih cukup tinggi dengan angka prediksi minimal 3.886 orang / tahun. Prediksi kebutuhan tenaga ini meliputi beberapa kualifikasi : data entri, operator, teknisi, programmer, administrator jaringan, Pustakawan, Broadcasting dan desain grafis. Kebutuhan tenaga terbesar yakni $23,70 \%$ diperoleh untuk tenaga kualifikasi programmer. Tuntutan kualifikasi kebutuhan tenaga teknologi informasi dan komunikasi yang bervariasi mengarahkan pada kurikulum Diploma III Teknologi Informasi hendaknya mendukung tercetaknya alumni yang mempunyai kemampuan praktis dan terampil sehingga terpenuhinya tuntutan tenaga-tenaga programmer handal pada bidangnya. Dilihat dari ketersediaan sumberdaya, kepemilikan UNDIKSHA Singaraja terhadap sumberdaya manusia maupun prasarana dan sarana sudah cukup memadai untuk menopang pembukaan program Diploma III Teknologi Informasi.
\end{abstract}

Kata kunci: studi kelayakan, teknologi informasi dan komunikasi, kuisioner. 


\begin{abstract}
Bali, was known as famous tourism region, have many possibility of social improvement, which is new job field opportunity that absorb many employee with spesific skills and qualifications. Major of those is concerned with tourism industry and the support systems, such as tourism guide, travel agent, hotel, spa, art shops, small-home-craft industries, including information technology supports. Early, market demand of Information Technology is increasing for years, especially in Bali region. It is mean that power with information technology skills is still needed. In order to know those requirements, fit and proper observation was held with quistionnaire media. The analysis of quistionnaire result shows that the needed of information technology graduate is relatively high, with estimating number 3.886 at least per year. This prediction including some of qualifications, which are data entry, computer operator, technician, programmer, network administrator, librarian, broadcasting technician, and graphics designer, which $23,70 \%$ is in programmer field. Based on that condition, the Information Technology diplomas curriculum should be adapted to fulfill the market demand and produce the professional and handfully graduates that can compete in certain fields. With any fasility, man power, and system in UNDIKSHA, this is possible to open the Information Technology Diplomas programs.
\end{abstract}

Key word : Visibility Study, fit and proper, information technology, questionnaire

\title{
I. Pendahuluan
}

Salah satu misi UNDIKSHA Singaraja adalah menyelenggarakan Tridarma Perguruan Tinggi dalam bidang kependidikan dan nonkependidikan untuk menghasilkan sumberdaya manusia yang berkualitas tinggi dalam bidang akademik, profesi dan vocasi. Pencetakan tenaga akademik dan atau profesional di bidang non-kependidikan sejalan dengan kebijakan pemerintah yang memberikan perluasan mandat (wider mandate) kepada lembaga-lembaga pendidikan tenaga kependidikan (LPTK) untuk mengelola bidang-bidang non-kependidikan di samping bidang kependidikan sebagai mandat utamanya. Perluasan mandat yang diberikan kepada UNDIKSHA sampai saat ini mayoritas diberdayakan melalui pembukaan jurusan / program studi bidang non-kependidikan setara D-3. Sampai dengan tahun 2006, UNDIKSHA Singaraja telah 
membuka 10 (sepuluh) jurusan / program studi setingkat D-3, dan 1 (satu) program studi setingkat S-1.

Pembukaan program-program non-kependidikan setingkat D-3 bertujuan menghasilkan tenaga-tenaga profesional ahli madya yang mengutamakan peningkatan kemampuan penerapan ilmu pengetahuan (pengetahuan praktis). Dalam pada itu, konteks Bali sebagai daerah tujuan wisata (DTW) yang makin mengglobal memberikan sejumlah peluang dan tantangan, seperti : terbukanya sejumlah lapangan kerja baru, baik dalam jenis, jumlah, dan jenjang kualifikasi tertentu. Lapangan pekerjaan itu sebagian besar bertalian langsung dengan industri pariwisata serta sistem pendukungnya. Misalnya, jasa bahasa asing (Inggris dll), manajemen bisnis dan akuntansi, pemandu wisata, biro perjalanan, pengelolaan hotel, sport dan rekreasi, kesenian, produk industri kecil/kerajinan, termasuk teknologi informasi.

Secara umum maupun secara khusus di Bali, sampai saat ini bidang teknologi informasi sudah memasuki hampir seluruh cabang kehidupan dengan kecenderungan yang semakin meningkat. Konteks Bali sebagai daerah tujuan wisata utama sangat banyak memerlukan sumber daya manusia yang handal di bidang teknologi informasi. Staf kantor depan (front office), kehumasan (public relations) di hotel, restoran, biro perjalanan atau usaha kargo sudah dituntut mampu menguasai teknologi informasi, khususnya teknologi informasi berbasis komputer, yang lebih dikenal dengan information and communication technology. Bahkan, kehumasan di lembaga-lembaga pemerintah juga sudah memerlukan sumber daya manusia yang terampil di bidang teknologi informasi berbasis komputer. Selanjutnya, perpustakaan di berbagai instansi, selain dituntut memiliki pengetahuan tentang perpustakaan secara manual, juga dituntut mengusai pengetahuan dan keterampilan pengelolaan perpustakaan terkomputerisasi. Situasi yang demikian akan memerlukan sumberdaya manusia yang handal dalam bidang teknologi informasi yang semakin banyak. Selain itu, kualitas sumberdaya manusia di bidang 
teknologi informasi yang diperlukan pasar juga semakin meningkat. Program Diploma-III Teknologi Informasi yang diusulkan diharapkan dapat memenuhi kebutuhan pasar akan sumberdaya manusia yang terampil di bidang teknologi informasi.

Berdasarkan uraian pada latar belakang, pada penelitian studi kelayakan ini perlu didapatkan klarifikasi terhadap pertanyaanpertanyaan berikut, (1) bagimanakah deskripsi kompetensi lulusan program D3 Teknologi Informasi yang dibutuhkan oleh pasar kerja?, (2) bagaimanakah potensi kebutuhan lulusan program D3 Teknologi Informasi oleh pasar kerja?, (3) bagaimanakah potensi lulusan SMU atau SMK yang relevan untuk melanjutkan studi pada program D3 Teknologi Informasi?, (4) bagaimanakah kesiapan UNDIKSHA dalam mengelola program D3 Teknologi Informasi?, (5) berapa besarkah proyeksi kebutuhan calon mahasiswa pada program D3 Teknologi Informasi?.

Adapun tujuan yang ingin dicapai dari penelitian ini adalah: (1) mendapatkan informasi tentang deskripsi kompetensi lulusan program D3 Teknologi Informasi yang dibutuhkan oleh pasar kerja, (2) mendapatkan informasi tentang potensi kebutuhan lulusan program D3 Teknologi Informasi oleh pasar kerja, (3) mendapatkan informasi tentang potensi lulusan SMU atau SMK yang relevan untuk melanjutkan studi pada program D3 Teknologi Informasi, (4) mendeskripsikan kesiapan UNDIKSHA dalam mengelola program D3 Teknologi Informasi, (5) memperoleh gambaran terkait dengan proyeksi calon mahasiswa yang bisa diterima pada program D3 Teknologi Informasi.

Berpedoman pada visi UNDIKSHA Singaraja, visi FTK UNDIKSHA Singaraja adalah menghasilkan sumberdaya manusia handal di bidang teknologi dan kejuruan dengan berdasar kepada Pancasila dan Undang-Undang Dasar 1945. Sumberdaya handal di bidang teknologi dan kejuruan dihasilkan melalui pelaksanaan Tri Dharma Perguruan Tinggi, yaitu pendidikan, penelitian, dan pengabdian pada masyarakat. Di bidang pendidikan dan pengajaran, sampai dengan 
tahun 2007, FTK baru mengelola 5 (lima) jurusan, tiga di antaranya untuk bidang teknologi dan dua lainnya untuk bidang kejuruan. Kelima jurusan tersebut adalah : jurusan PKK (S-1), jurusan Manajemen Informatika (D3), jurusan Teknik Elektro (D-3), jurusan Boga Perhotelan (D-3), dan Jurusan Pendidikan Teknologi Informatika dan Komputer (S1).

Rencana strategis 2004-2010 FTK UNDIKSHA Singaraja merencanakan pengembangan jurusan-jurusan yang sudah ada serta membuka jurusan-jurusan baru yang potensial memenuhi kebutuhan sumberdaya pendukung pembangunan di tingkat lokal, nasional, maupun di tingkat global. Pengembangn jurusan di lingkungan FTK yang sudah dirancang untuk lima tahun mendatang seperti tampak pada tabel 1.

Tabel 1. Rencana Pengembangan Jurusan Di Lingkungan FTK

\begin{tabular}{|c|l|c|l|c|}
\hline NO & \multicolumn{1}{|c|}{ JURUSAN } & STRATA & \multicolumn{1}{|c|}{ BIDANG } & $\begin{array}{c}\text { TAHUN } \\
\text { PEMBUKAAN }\end{array}$ \\
\hline 1 & Teknik Elektro & S-1 & Kependidikan & 2007 \\
\hline 2 & Teknik Mesin & D-3 & Non-kependidikan & 2007 \\
\hline 3 & Boga Perhotelan & D-4 & Non-kependidikan & 2008 \\
\hline \multicolumn{7}{|c}{ Menurut Undang-undang } & RI No. 20 Tahun 2003 tentang
\end{tabular}

SISDIKNAS bahwa, Sistem pendidikan nasional menetapkan jenjang pendidikan formal meliputi pendidikan dasar, pendidikan menengah dan pendidikan tinggi. Pendidikan tinggi merupakan jenjang pendidikan setelah pendidikan menengah yang mencakup program pendidikan diploma, sarjana, magister, spesialis, dan doktor yang diselenggarakan oleh perguruan tinggi. Penyelenggaran pendidikan dan pengembangan ilmu pengetahuan pada perguruan tinggi memberlakukan kebebasan akademik dan kebebasan mimbar akademik serta otonomi keilmuan. Perguruan tinggi memiliki otonomi untuk mengelola sendiri lembaganya sebagai pusat penyelenggaraan pendidikan tinggi, penelitian ilmiah, dan pengabdian kepada masyarakat. Perguruan tinggi juga berhak memperoleh sumber dana dari masyarakat yang pengelolaannya dilakukan berdasarkan prinsip akuntabilitas publik.

\section{Metode Penelitian}

Studi Kelayakan Pembukaan Diploma........(Komang Setemen, dkk) 
Penelitian ini merupakan penelitian studi kelayakan dalam rangka memberdayakan perluasan mandat yang telah diberikan oleh pemerintah kepada UNDIKSHA Singaraja. Dalam penelitian ini pemberdayaan perluasan mandat difokuskan pada pembukaan Jurusan D3 Teknologi Informasi pada Fakultas Teknik dan Kejuruan UNDIKSHA Singaraja.

Penelitian ini dilaksanakan di jurusan Manajemen Informatika FTK UNDIKSHA Singaraja dan di beberapa instansi pemerintah maupun swasta di Bali yang terkait. Instansi pemerintah atau swasta yang dimaksud adalah instansi yang bergerak pada jasa teknologi informasi, baik dalam kapasitas sebagai pengguna maupun sebagai pengembang. Instansi pemerintah maupun swasta tersebut meliputi :

a). Kehumasan dan Kantor Depan

b). Perpustakaan

c). Lembaga-lembaga lain yang bergerak di bidang informasi, seperti: Stasiun TV, Stasiun Radio, Dinas Informasi, Rumah Produksi Film, atau Rumah Produksi Multimedia.

Subyek penelitian meliputi staf edukatif jurusan Manajemen Informatika, staf pada instansi pemerintah dan swasta yang operasionalnya memanfaatkan jasa teknologi informasi, serta siswa SMA atau SMK yang relevan sebagai calon mahasiswa. Populasi penelitian adalah instansi pemerintah dan swasta yang bergerak dibidang TI atau yang memanfaatkan jasa TI, serta siswa SMA atau SMK yang relevan yang ada di Bali.

Data yang dibutuhkan dalam penelitian ini meliputi data primer dan data sekunder. Data primer meliputi dukungan kesiapan calon pengguna, informasi penekanan spesifikasi kebutuhan tenaga teknologi informasi pada masing-masing instansi pemerintah maupun swasta, serta minat calon mahasiswa untuk melanjutkan pendidikannya di Jurusan D3 Teknologi Informasi. Data sekunder yang dibutuhkan meliputi analisis persyaratan tuntutan kurikulum sesuai dengan perundang-undangan yang 
berlaku, dukungan prasarana dan sarana pendukung PBM, dan curiculum vitae staf dosen jurusan Manajemen Informatika.

Data primer dikumpulkan melalui kuisioner yang disusun bersama oleh tim peneliti. Kuisioner ini terlebih dahulu dikonsultasikan dengan pihak-pihak pengambil kebijakan di lingkungan UNDIKSHA. Kuisioner yang digunakan bersifat terbuka sehingga diharapkan penelitian dapat memberikan informasi secara utuh. Untuk lebih meyakinkan keutuhan informasi yang diperoleh, pengumpulan data primer juga dilakukan melalui wawancara dengan sumber informasi. Pengumpulan data skunder dilakukan melalui studi dokumen perundang-undangan yang terkait, dan curriculum vitae staf.

Cakupan data dilihat dari sumber data, jenis data, metode, dan instrumen yang digunakan dalam pengumpulan data dituangkan dalam tabel 2 berikut.

Tabel 2. Cakupan data penelitian

\begin{tabular}{|c|c|c|c|c|}
\hline NO & $\begin{array}{l}\text { SUMBER } \\
\text { DATA }\end{array}$ & JENIS DATA & METODE & INSTRUMEN \\
\hline \multirow[t]{5}{*}{1} & Instansi & Tugas-tugas / / & \multirow{4}{*}{$\begin{array}{l}\text { Kuisioner } \\
\text { Wawancara }\end{array}$} & \multirow{4}{*}{$\begin{array}{l}\text { Kuisioner } \\
\text { Pedoman } \\
\text { wawancara }\end{array}$} \\
\hline & $\begin{array}{l}\text { Pemerintah } \\
\text { dan Swasta }\end{array}$ & $\begin{array}{l}\text { Spesifikasi } \\
\text { / Kualifikasi }\end{array}$ & & \\
\hline & & $\begin{array}{l}\text { Prospek penyerapan } \\
\text { tenaga alumni }\end{array}$ & & \\
\hline & & $\begin{array}{l}\text { Proyeksi kebutuhan } \\
\text { tenaga alumni }\end{array}$ & & \\
\hline & $\begin{array}{l}\text { Calon } \\
\text { Mahasiswa }\end{array}$ & $\begin{array}{l}\text { Minat calon } \\
\text { mahasiswa }\end{array}$ & $\begin{array}{l}\text { Kuisioner } \\
\text { Pencatatan } \\
\text { Dokumen }\end{array}$ & $\begin{array}{l}\text { Kuisioner } \\
\text { Formulir }\end{array}$ \\
\hline \multirow[t]{2}{*}{2} & \multirow[t]{2}{*}{ UNDIKSHA } & Kesiapan SDM & $\begin{array}{l}\text { Pencatatan } \\
\text { Dokumen }\end{array}$ & Formulir \\
\hline & & $\begin{array}{ll}\text { Kesiapan } & \text { Sumber } \\
\text { Daya } & \\
\text { Fasilitas } & \\
\end{array}$ & $\begin{array}{l}\text { Pencacatan } \\
\text { Dokumen } \\
\text { Observasi } \\
\end{array}$ & $\begin{array}{l}\text { Formulir } \\
\text { Pedoman } \\
\text { Observasi }\end{array}$ \\
\hline
\end{tabular}

Data yang terkumpul selanjutnya dianalisis secara kualitatif. Persyaratan tuntutan kurikulum dideskripsikan berdasarkan ketentuanketentuan yang tertera pada peraturan perundang-undangan yang berlaku. Dukungan kesiapan masing-masing komponen terlebih dahulu di tabulasikan per komponen, selanjutnya dianalisis berdasarkan persyaratan 
kebutuhan penyelenggaraan program. Data kesiapan sebagai pengguna maupun bidang unggulan yang dibutuhkan oleh calon pengguna, terlebih dahhulu juga ditabulasi berdasarkan sebaran internal yang terkumpul untuk selanjutnya dicermati bidang-bidang unggulan yang memiliki konsentrasi peminat paling tinggi.

\section{Hasil Penelitian dan Pembahasan}

\subsection{Sumber Data}

Berdasarkan perencanaan awal terkait dengan sumber data penelitian, instansi/badan yang memenuhi permohonan pengumpulan data penelitian studi kelayakan ini meliputi:

1. Instansi Pendidikan, yaitu UNDIKSHA dan SMA Negeri yang ada di Kabupaten Buleleng dan Beberapa SMA Negeri di Denpasar

2. Perbankan, yaitu BANK BUMN maupun swasta yang ada di Singaraja dan beberapa di Denpasar

3. Perseroan Terbatas, yaitu PT milik pemerintah yang ada di Singaraja dan beberapa di Denpasar

4. Penyiaran dan Perusahaan Rekaman, yaitu lembaga penyiaran publik milik pemerintah (RRI) dan perusahaan penyiaran dan rekaman swasta yang ada di Denpasar

5. Software House, yaitu beberapa perusahaan swasta sebagai pengembang Software di Denpasar

6. Hotel, yaitu beberapa Hotel berbintang di daerah Singaraja dan Denpasar

7. Lain-lain, yaitu masyarakat umum di Singaraja.

Adapun keterkaitan antara penentuan instansi dengan kebutuhan data penelitian, adalah berkaitan dengan hal-hal sebagai berikut:

1. Ketersediaan prasarana dan sarana yaitu perangkat keras dan perangkat lunak 
2. Keberadaan Sumber Daya Manusia yang akan mengelola Jurusan yang diusulkan

3. Ketersediaan buku-buku teks penunjang dalam proses pembelajaran

4. Minat calon mahasiswa untuk masuk pada Jurusan yang akan diusulkan

5. Proyeksi tuntutan kualifikasi lulusan yang inginkan oleh pasar

6. Proyeksi kebutuhan tenaga alumni setiap tahunnya

7. Tuntutan deskripsi kurikulum yang ditawarkan

\subsection{Minat Masyarakat}

Minat masyarakat dijaring melalui masukan dari Siswa-siswi SMA yang sudah dideskripsikan sebelumnya dan Karyawan / Karyawati dari instansi pemerintah maupun swasta, serta masyarakat umum yang mempunyai anak yang sedang duduk di sekolah SMA. Secara umum masyarakat memiliki keinginan tinggi untuk dapat menimba ilmu di jurusan Teknologi Informasi. Prediksi ini didukung oleh data yang berhasil dikumpulkan melalui kuisioner seperti tertera pada tabel 3.

Tabel 3: Distribusi Jurusan yang Diminati oleh Siswa SMA atau SMK

\begin{tabular}{|c|l|r|r|}
\hline NO & \multicolumn{1}{|c|}{$\begin{array}{c}\text { JURUSAN YANG } \\
\text { DIMINATI }\end{array}$} & JUMLAH & PERSENTASE \\
\hline & $\begin{array}{l}\text { Teknologi Informasi dan } \\
\text { Komunikasi }\end{array}$ & 118 & $68,60 \%$ \\
\hline 2 & Teknik Industri & 12 & $6,98 \%$ \\
\hline 3 & Teknik Elektro & 17 & $9,88 \%$ \\
\hline 4 & Jurusan Lainnya & 25 & $14,53 \%$ \\
\hline & T O T A L & 172 & $100,00 \%$ \\
\hline
\end{tabular}

Dari Tabel 3 terlihat bahwa dari 172 orang responden, 118 di antaranya ingin melanjutkan pendidikannya di Jurusan Teknologi Informasi dan Komunikasi, 2 orang ingin melanjutkan pendidikannya di Jurusan Teknik Industri, 17 orang ingin melanjutkan pendidikannya pada Jurusan Teknik Elektro dan 25 orang melanjutkan pendidikannya pada 
Jurusan lain. Dengan kata lain, dari 172 responden sebesar 68,60\% lulusan SMA atau SMK berminat melanjutkan studi di Jurusan Teknologi Informasi dan Komunikasi. Sedangkan dilihat dari keinginan orang tua mengarahkan anaknya untuk melanjutkan studi setelah tamat SMA atau SMK dapat dilihat pada Tabel 4 berikut.

Tabel 4: Pilihan Orangtua dalam Mengarahkan Pendidikan Anak

\begin{tabular}{|c|l|r|r|}
\hline NO & $\begin{array}{l}\text { JURUSAN YANG } \\
\text { DISARANKAN }\end{array}$ & JUMLAH & \multicolumn{1}{|l|}{ PERSENTASE } \\
\hline 1 & Ilmu-ilmu Teknologi & 91 & $61,49 \%$ \\
\hline 2 & Ilmu-ilmu Pariwisata & 11 & $7,43 \%$ \\
\hline 3 & Ilmu-ilmu Sosial & 11 & $7,43 \%$ \\
\hline 4 & Ilmu-ilmu Eksakta/MIPA & 23 & $15,54 \%$ \\
\hline 5 & Ilmu-ilmu Lainnya & 12 & $8,11 \%$ \\
\hline & T O T A L & 148 & $100,00 \%$ \\
\hline
\end{tabular}

\subsection{Proyeksi Kebutuhan Sumberdaya TIK}

Lulusan Program Diploma III Teknologi Informasi diproyeksikan untuk memenuhi kebutuhan tenaga TIK pada instansi/badan pemerintah atau swasta yang memanfaatkan jasa TIK pada bidang kerjanya. Instansi/badan tersebut meliputi software house, Perseroan Terbatas, Bank, Penyiaran dan Perusahaan Rekaman, Hotel dan yang lainnya. Dari 205 kuisioner yang kembali, sebanyak 136 responden sudah memiliki prediksi kebutuhan tenaga TIK di instansi/badan tempat mereka bekerja. Dari sejumlah responden ini sebaran prediksi kebutuhan tenaga TIK diberikan seperti pada Tabel 5 .

Tabel 5: Prediksi Kebutuhan Tenaga TIK Per Tahun pada Instansi/Badan Pemerintah atau Swasta

\begin{tabular}{|c|c|r|c|}
\hline NO & $\begin{array}{l}\text { KEBUTUHAN TENAGA } \\
\text { TIK PER TAHUN }\end{array}$ & JUMLAH & PERSENTASE \\
\hline 1 & $>50$ & 43 & $31,62 \%$ \\
\hline 2 & $26-50$ & 61 & $44,85 \%$ \\
\hline 3 & $10-25$ & 15 & $11,03 \%$ \\
\hline 4 & $<10$ & 17 & $12,50 \%$ \\
\hline \multicolumn{2}{|c|}{ TOTAL } & 136 & $100,00 \%$ \\
\hline
\end{tabular}

Ditinjau dari kualifikasi strata pendidikan, sebaran kebutuhan tenaga teknologi informasi ditunjukkan seperti pada tabel 6 . 
Tabel 6: Proyeksi Kebutuhan Tenaga TIK Berdasarkan Strata Pendidikan

\begin{tabular}{|c|l|r|r|}
\hline NO & $\begin{array}{c}\text { KUALIFIKASI JENJANG } \\
\text { PENDIDIKAN }\end{array}$ & JUMLAH & PERSENTASE \\
\hline 1 & SMA/SMK & 11 & $7,28 \%$ \\
\hline 2 & D3 & 27 & $17,88 \%$ \\
\hline 3 & S1 & 100 & $66,23 \%$ \\
\hline 4 & S2 & 13 & $8,61 \%$ \\
\hline \multicolumn{2}{|l|}{ TOTAL } & 151 & $100,00 \%$ \\
\hline
\end{tabular}

Berdasarkan data pada tabel 6 , tampak bahwa kebutuhan tenaga dengan kualifikasi strata pendidikan D3 memiliki persentase tertinggi kedua setelah pendidikan S-1. Interpretasi yang dirumuskan yaitu tenaga lulusan S-1 diperkirakan lebih mudah mendapatkan lapangan kerja dibandingkan dengan kualifikasi strata pendidikan lainnya.

Selain itu, luasnya cakupan bidang TIK perlu juga disikapi dengan pemerataan sebaran kualifikasi keterampilan lulusan sehingga tidak mengakibatkan penumpukan alumni di satu bidang dan sebaliknya kekurangan di bidang yang lain. Dengan kata lain perlu pula ditinjau cakupan sebaran kualifikasi yang dibutuhkan beserta kuantitas kebutuhannya. Data terkait dengan sebaran kualifikasi yang dibutuhkan beserta kuantitas kebutuhan diterakan pada Tabel 7 berikut.

Tabel 7: Sebaran Kualifikasi Kebutuhan Tenaga Teknologi Informasi

\begin{tabular}{|r|l|r|r|}
\hline NO & $\begin{array}{l}\text { KUALIFIKASI YANG } \\
\text { DIBUTUHKAN }\end{array}$ & JUMLAH & \multicolumn{1}{|l|}{ PERSENTASE } \\
\hline 1 & Data Entri & 24 & $11,37 \%$ \\
\hline 2 & Operator TI & 26 & $12,32 \%$ \\
\hline 3 & Tenaga Teknisi & 48 & $22,75 \%$ \\
\hline 4 & Programmer & 50 & $23,70 \%$ \\
\hline 5 & Administrator Jaringan & 14 & $6,64 \%$ \\
\hline 6 & Desain Grafis & 31 & $14,69 \%$ \\
\hline 7 & Pustakawan & 6 & $2,84 \%$ \\
\hline 8 & Broadcasting & 5 & $2,37 \%$ \\
\hline 9 & Kualifikasi lain & 211 & $3,32 \%$ \\
\hline & T O T A L & & $100,00 \%$ \\
\hline
\end{tabular}


Dilihat dari tabel tersebut, tampak bahwa kualifikasi tenaga sebagai programmer memiliki persentase kebutuhan paling tinggi yakni sebesar 23,70\%. Dengan demikian sebaran kurikulum Diploma III Teknologi Informasi hendaknya diarahkan agar mahasiswa nantinya memiliki keterampilan sebagai seorang programmer dan sekaligus sebagai problem solver dari persoalan-persoalan manual yang akan ditemui di lapangan.

\subsection{Tuntutan Kualifikasi Kompetensi Lulusan}

Jurusan Diploma III Teknologi Informasi disiapkan untuk menghasilkan tenaga ahli madya yang memiliki kemampuan praktis pada bidang komputasi. Program ini difokuskan pada penerapan dan pemanfaatan Teknologi Informasi dan Komunikasi (ICT) untuk menunjang efektivitas penyelenggaraan suatu badan/instansi, baik badan/instansi pemerintah maupun swasta. Disamping itu tenaga ahli madya yang dihasilkan dituntut pula memiliki kemampuan menganalisis perkembangan teknologi, serta relevansi implikasinya pada peningkatan perekonomian dan status sosial masyarakat.

Berdasarkan karakteristik tenaga ahli madya yang dihasilkan oleh jurusan Diploma III Teknologi Informasi, maka kompetensi yang mesti dimiliki oleh lulusan meliputi :

1. mampu mengembangkan diri di bidang Teknologi Informasi dan Komunikasi

2. mampu menggunakan sistem yang berbasis TIK

3. mampu menerapkan keterampilan dan konsep TIK dalam mendukung kelancaran tugas-tugas badan/instansi tempatnya bekerja

4. mampu memposisikan sistem TIK secara tepat sebagai bagian dari keseluruhan sistem yang ada

5. mampu bekerjasama secara efektif dalam suatu tim

6. memiliki kemampuan komunikasi yang komunikatif dengan tim

Peran teknologi informasi dan komunikasi (TIK) dalam mendukung perkembangan instansi/badan maupun dunia usaha/industri 
dewasa ini sangat vital. TIK sudah merambah di berbagai sektor, tidak hanya di instansi/badan dan perusahaan yang menjadikan TIK sebagai pekerjaan utamanya, tetapi juga instansi/badan dan perusahaan lain dengan pekerjaan yang justru tidak ada hubungannya dengan TIK. Disinilah TIK berfungsi sebagai sarana pendukung instansi/badan dan dunia industri yang teramat vital.

Hal ini terbukti dari jumlah tenaga kerja yang dibutuhkan untuk berbagai sektor, tenaga kerja TIK menempati urutan pertama (WorkforceIBM, 2006 dalam Zainal Hasibuan, 2007). Khusus untuk Indonesia, hal ini ditandai dengan bermunculannya berbagai program studi yang menawarkan bidang yang terkait dengan teknologi informasi. Saat ini diperkirakan ada sekitar 700 dari sekitar 2300 perguruan tinggi di Indonesia yang memiliki program studi yang terkait dengan TIK.

Disiplin ilmu Teknologi Informasi dan Komunikasi merupakan sebuah disiplin ilmu yang tidak mungkin dapat dipisahkan dengan berbagai bidang kehidupan. Disiplin ilmu ini muncul sebagai bagian dari beragam bidang kehidupan sehingga penerapannyapun tidak mungkin pula dihindarkan pada keseluruhan bidang kegiatan, badan maupun instansi. Ditambah lagi dengan kemajuan yang sangat pesat di dunia teknologi dan informasi sehingga mampu menyediakan variasi serta kualitas layanan yang semakin meluas. Kondisi ini semakin meyakinkan bahwa tidak ada satupun bidang kehidupan yang tidak mungkin tersentuh oleh bidang teknologi informasi dan komunikasi.

Fakta ini perlu disikapi secara lebih arif bahwa teknologi dalam batasan perangkat keras bukanlah merupakan kunci keberhasilan dalam penerapannya. Di balik batasan ini masih ada komponen yang lebih penting yakni sumberdaya manusia. Eksistensi sumberdaya manusia yang handal memiliki andil yang lebih dominan dibandingkan dengan perangkat kerasnya sendiri. Melihat sedemikian dominannya kontribusi sumberdaya manusia dalam penerapan teknologi informasi maka sudah semestinya kebutuhan sumberdaya ini dipenuhi melalui pendidikan 
formal Diploma III Teknologi Informasi, sehingga penerapan teknologi informasi dan komunikasi betul-betul dapat secara optimal memberikan kontribusi kepada berbagai bidang kehidupan yang ditopangnya. Di satu sisi, berdasarkan data penelitian ditunjukkan kebutuhan tenaga di bidang teknologi informasi dan komunikasi cukup tinggi. Data ini dapat dilihat dari proyeksi kebutuhan pasar yakni dengan perkiraan kebutuhan minimal tenaga 3.886 orang / tahun diyakini cukup menjanjikan bahwa alumni jurusan Diploma III Teknologi Informasi pasti akan terserap di pasar kerja untuk memenuhi kebutuhan pada berbagai kualifikasi yang dibutuhkan.

Disamping itu ditinjau dari keberadaan sumberdaya baik yang menyangkut sumberdaya manusia maupun sumberdaya prasarana dan sarana FTK Undiksha Singaraja, sudah cukup memadai untuk ditugaskan mengelola jurusan Diploma III Teknologi Informasi. Sampai dengan tahun 2007, jurusan D-3 Manajemen Informatika memiliki 11 (sebelas) tenaga tetap jurusan di mana satu orang diantaranya berpendidikan S-3, 4 orang berpendidikan S-2, dan 6 orang sisanya berpendidikan S-1 (perhatikan tabel 10). Dari 6 orang tenaga jurusan yang tercatat berpendidikan S-1, 4 orang di antaranya sedang menjalani studi lanjut S-2 di Institut Teknologi Sepuluh Nopember Surabaya. Selain itu dilihat dari keberadaan tenaga administrasi dan tenaga penunjang akademik, FTK sebagai fakultas induk jurusan Diploma III Teknologi Informasi sudah memiliki 5 orang tenaga administrasi berpendidikan S-1, dan 2 orang tenaga penunjang akademik berpendidikan SMA. Dengan demikian dari pemenuhan tenaga administrasi sudah mencukupi, namun kekurangan tenaga penunjang akademik direncanakan memanfaatkan secara optimum tenaga pada UPT Puskom yang memiliki latar belakang pendidikan formal D-3 Manajemen Informatika. Dari dukungan prasarana dan sarana yang menyangkut ruang perkuliahan, ruang laboratorium, ruang administrasi dan perpustakaan, sudah cukup memadai untuk pembukaan jurusan Diploma III Teknologi Informasi. 


\section{Penutup}

Berdasarkan pencermatan dari data yang terkumpul serta rujukan pada keputusan yang mengatur tentang persyaratan pembukaan program studi dan / atau jurusan, maka dapat disimpulkan bahwa :

a). Berdasarkan proyeksi kebutuhan tenaga Teknologi Informasi dan Komunikasi yang dijaring melalui kuisioner penelitian, didapat bahwa pasar masih sangat membutuhkan tenaga alumni jurusan Diploma III Teknologi Informasi. Khususnya untuk di Bali, kebutuhan tenaga ini belum didukung oleh keberadaan Perguruan Tinggi Negeri yang mengelola jurusan ini melalui kelas reguler. Dengan demikian pembukaan Jurusan Diploma III Teknologi Informasi di lembaga Universitas Pendidikan Ganesah Singaraja dipandang cukup tepat untuk memenuhi kebutuhan pasar tenaga kerja di bidang teknologi informasi dan komunikasi.

b). Kualifikasi kebutuhan tenaga teknologi informasi dan komunikasi di pasar kerja cukup bervariasi. Fakta ini relevan dengan keberadaan disiplin ilmu dari teknologi informasi dan komunikasi yang multi disiplin. Kualifikasi tersebut meliputi data entri, operator, teknisi, programmer, administrator jaringan, pustakawan, broadcasting, dan desain grafis.

c). Meskipun kualifikasi kebutuhan tenaga teknologi informasi dan komunikasi cukup bervariasi, akan tetapi dari tabel 10 terlihat bahwa kebutuhan tenaga paling banyak adalah pada tenaga programmer. Oleh karena itu sebaran kurikulum jurusan Diploma III Teknologi Informasi hendaknya mendukung tercetaknya alumni kemampuan praktis dan terampil sehingga terpenuhinya tuntutan tenaga-tenaga programmer handal pada bidangnya.

d). Keberadaan sumberdaya yang meliputi sumberdaya manusia maupun sumberdaya prasarana dan sarana sudah cukup memadai untuk 
mendukung pembukaan jurusan Diploma III Teknologi Informasi di FTK UNDIKSHA Singaraja.

Berdasarkan temuan-temuan pada penelitian ini maka disarankan kepada jurusan, fakultas, dan lembaga UNDIKSHA Singaraja :

a). segera menindaklanjuti usulan pembukaan jurusan Diploma III Teknologi Informasi sehingga pemenuhan kebutuhan pasar tenaga teknologi informasi dan komunikasi secepatnya tercapai.

b). karena keterbatasan kemampuan tim peneliti, barangkali masih ada pertimbangan yang belum sempat dicermati tetapi menurut pertimbangan pembaca beberapa hal tersebut memiliki kontribusi yang sangat penting bagi keberhasilan studi ini maka dengan senang hati tim mengharapkan adanya saran atau pertimbangan demi penyempurnaan pelaksanaan studi kelayakan ini.

\section{DAFTAR PUSTAKA}

Tim, 2003, Undang-Undang Republik Indonesia Nomor 20 Tahun 2003 tentang Sistem Pendidikan Nasional, Biro Hukum dan Organisasi Sekjen Depdiknas, Jakarta

Tim, 2004, Rencana Strategis Fakultas Pendidikan Teknologi dan Kejuruan, IKIP Negeri Singaraja.

Zainal Hasibuan, 2007. Kontribusi Dunia Pendidikan dalam Bidang Teknologi Informasi untuk Dunia Usaha/Industri. Makalah disampaikan pada Seminar Jurusan Manajemen Informatika tanggal 7 Mei 2007 